\title{
Usefulness of sRtot and Rint in bronchodilator testing in the diagnosis of asthma in children
}

\author{
Monika Bobrowska-Korzeniowska¹, Agnieszka Brzozowska1, Joanna Jerzyńska ${ }^{1}$, Włodzimierz Stelmach², \\ Iwona Stelmach ${ }^{1}$
}

${ }^{1}$ Department of Paediatrics and Allergy, N. Copernicus Memorial Hospital, Medical University of Lodz, Lodz, Poland ${ }^{2}$ Social Medicine Institute, Department of Social and Preventive Medicine, Medical University of Lodz, Lodz, Poland

Adv Dermatol Allergol 2020; XXXVII (5): 685-689

DOI: https://doi.org/10.5114/ada.2019.85631

\begin{abstract}
Introduction: The usefulness of total specific resistance (sRtot) and interrupter resistance (Rint) as a bronchodilator reversibility test $(\mathrm{BT})$ alternative to forced expiratory volume in $1 \mathrm{~s}\left(\mathrm{FEV}_{1}\right)$ in asthma diagnosis in children has not been established.

Aim: To compare different applied definitions of airflow obstruction in children measuring response to the bronchodilator by spirometry, plethysmography and the interrupter technique in asthmatic children.

Material and methods: It was a prospective, real-life, non-interventional study. Children, aged 6-18 with newly diagnosed asthma, able to perform lung function tests were included into the study. Subjects underwent a history taking, physical examination, reversibility test in spirometry, plethysmography, and the interrupter technique. A standard cut-off of $12 \%$ from the initial value for reversibility in FEV ${ }_{1}$ was employed. Improvement in the prebronchodilator sRtot and Rint $\geq 25 \%$ and $\geq 35 \%$ was assessed after administration of salbutamol $(400 \mu \mathrm{g})$ as well as allergen sensitization were measured.

Results: We included 135 children diagnosed with asthma into the analysis. All investigated parameters changed statistically significantly due to the bronchodilator administration in the examined patients. The FEV ${ }_{1}$ was not as useful in diagnostics of asthma as the sRtot and Rint, taking into consideration the fait accompli that all the study participants had aptly been diagnosed as having asthma $(p<0.001)$. The differences between the sRtot and Rint were not statistically significant $(p=0.215)$.

Conclusions: Our results suggest that sRtot and Rint may be useful parameters in BT in clinical practice in the asthma diagnostic process in children.
\end{abstract}

Key words: asthma, children, reversibility test, total specific resistance, interrupter resistance.

\section{Introduction}

Asthma is one of the most common chronic diseases and is associated with a variable airflow obstruction that is often reversible [1]. The clinical importance of a bronchodilator reversibility test (BT) is proven and the spirometry is the standard assessment technique for respiratory function according to standards [2]. The spirometry is the most widelyused lung function test in children. However, other methods assessing airway function that do not require complex respiratory manoeuvers are necessary. The most common methods for measurement of airway resistance that require less cooperation and less physical effort from the patient are plethysmography and the interrupter technique [3-6].

\section{Aim}

The aim of this study was to compare different applied definitions of airflow obstruction in children. We assessed the usefulness of forced expiratory volume in $1 \mathrm{~s}\left(\mathrm{FEV}_{1}\right)$, total specific resistance (sRtot) and interrupter resistance (Rint) in the bronchodilator reversibility test in clinical practice in children with asthma symptoms.

\section{Material and methods}

\section{Study design}

It was a prospective, real-life, non-interventional study. All children, aged 6-18, newly diagnosed with

Address for correspondence: Prof. Iwona Stelmach MD, PhD, Department of Paediatrics and Allergy, N. Copernicus Memorial Hospital, Medical University of Lodz, 71 Al. Pilsudskiego, 90-329 Lodz, Poland, phone: +48 4220747 26, fax: +48 426776358 ,

e-mail: alergol@kopernik.lodz.pl

Received: 10.01.2019, accepted: 7.02.2019. 
asthma according to GINA guidelines [1] in our Allergic Outpatient Clinic, between January 2015 and June 2017 and able to perform lung function tests, were included into the study. None of the patients was chronically treated with inhaled corticosteroids and/or leukotriene inhibitors. Subjects underwent a history taking, physical examination, spirometry, plethysmography and the interrupter technique. We decided to assess sRtot - one of the parameters which can be calculated from the specific airway resistance (sRaw) loop, since its sensitivity to partial obstruction of peripheral airways has been well established $[7,8]$. When airway reversibility was being assessed, a bronchodilator was administered (400 $\mu \mathrm{g}$ of salbutamol) using a spacer. After 15 min all respiratory tests were repeated. A standard cut-off of $12 \%$ of predicted value for reversibility in $\mathrm{FEV}_{1}$ was employed [1]. Improvement in the pre-bronchodilator sRtot and Rint after administration of salbutamol $\geq 25 \%$ and $\geq 35 \%$ was assessed [2, 6, 9].

Patients were classified as atopic based on the history and skin prick testing (SPT). In patients unable to undergo skin testing (either on antihistamine drugs or SPT results were not consistent with the clinical symptoms), a serum specific IgE for a specific allergen was employed. In patients with seasonal allergy, all lung function testing was done out of the pollen season. The diagnosis of asthma was universally established by the allergists according to the standard definition of the disease in the latest GINA guidelines.

\section{Ethics}

The study was approved by the Medical Ethics Committee of the Medical University of Lodz. All parents or legal guardians gave their oral and written consent to the evaluation of data from medical documentation of their children.
The study was registered on www.ClinicalTrials.gov, with ClinicalTrials.gov ID: NCT01805635.

\section{Detailed information on procedures}

Detailed information on the methods employed is available in our previous papers $[6,10,11]$ and in other authors' publications $[1,2,12,13]$.

\section{Statistical analysis}

The statistical power of the sample was as follows: for $\mathrm{FEV}_{1}$ (134 complete records), the statistical power was 99.99\%, for sRtot (124 complete records), it was $99.99 \%$, and for Rint (133 complete records), it was 99.99\%.

The investigated traits were described by way of measures of location - mean, median and quartiles, along with measures of dispersion - interquartile range, standard deviation, standard error of mean, 95\% confidence interval, and minimum-to-maximum values.

Mixed-effects linear regression models were carried out in order to test the significance of changes in the investigated respiratory and plethysmography parameters before and after salbutamol. Mixed-effects logistic regression models were employed for binary variables. All the regression equations were controlled for the studied patients' age and sex. Z-scores were also computed for Rint values and their changes during the study. A level of $p<0.05$ was considered statistically significant. All the statistical computations were carried out by means of Stata/Special Edition, release 14.2 (StataCorp LP, College Station, Texas, USA).

\section{Results}

We included 135 children diagnosed with asthma into the analysis. There were 56 (41.5\%) females. The studied patients' mean age was $10.2 \pm 2.7$ years. Of 135 children included into the study, all underwent spirometry, 122 of

Table 1. Descriptive statistics for selected measures of espiratory function in the studied patients before and after bronchodilator (salbutamol)

\begin{tabular}{|c|c|c|c|c|c|c|c|c|c|}
\hline \multirow{2}{*}{$\begin{array}{l}\text { Investigated } \\
\text { trait }\end{array}$} & \multirow{2}{*}{$\begin{array}{l}\text { Stage of } \\
\text { the study }\end{array}$} & \multicolumn{7}{|c|}{ Statistical parameter } & \multirow{2}{*}{$\begin{array}{l}\text { Level of } \\
\text { statistical } \\
\text { significance } \\
\text { (p-value) * }\end{array}$} \\
\hline & & $M$ & $\mathrm{Me}$ & $Q_{1}-Q_{3}(I Q R)$ & SD & SE & $95 \% \mathrm{Cl}$ & Min.-max. & \\
\hline \multirow[t]{2}{*}{$\mathrm{FEV}_{1}$ best [l] } & Before & 2.18 & 2.08 & $1.65-2.58(0.93)$ & 0.69 & 0.06 & $2.06-2.30$ & $1.03-4.41$ & \multirow[t]{2}{*}{$<0.001$} \\
\hline & After & 2.33 & 2.24 & $1.83-2.72(0.89)$ & 0.72 & 0.06 & $2.20-2.45$ & $1.09-4.80$ & \\
\hline \multirow{2}{*}{$\begin{array}{l}\mathrm{FEV}_{1} \text { best/ } \\
\text { predicted (\%) }\end{array}$} & Before & 94.43 & 94 & 86-102 (16) & 13.06 & 1.13 & $92.20-96.66$ & 53-137 & \multirow[t]{2}{*}{$<0.001$} \\
\hline & After & 100.45 & 100 & 93-110 (17) & 12.63 & 1.09 & 98.29-102.61 & $72-141$ & \\
\hline \multirow{2}{*}{$\begin{array}{l}\mathrm{SR}_{\text {tot }} \\
{[\mathrm{kPa} \times \mathrm{s}]}\end{array}$} & Before & 202.60 & 192.50 & $161.50-234(72.50)$ & 70.46 & 6.33 & 190.07-215.12 & $78-571$ & \multirow[t]{2}{*}{$<0.001$} \\
\hline & After & 138.90 & 131 & $113-160(47)$ & 40.54 & 3.64 & $131.70-146.11$ & 69-294 & \\
\hline \multirow[t]{2}{*}{$\mathrm{R}_{\mathrm{int}}[\mathrm{kPa} / \mathrm{l} / \mathrm{s}]$} & Before & 171.28 & 165 & $141-195$ (54) & 49.6 & 4.30 & $162.76-179.79$ & $77-384$ & \multirow[t]{2}{*}{$<0.001$} \\
\hline & After & 134.41 & 130 & $109-157(48)$ & 36.7 & 3.18 & $128.12-140.71$ & $51-222$ & \\
\hline
\end{tabular}

*All the repeated measures performed were controlled for the patients' age and sex. 

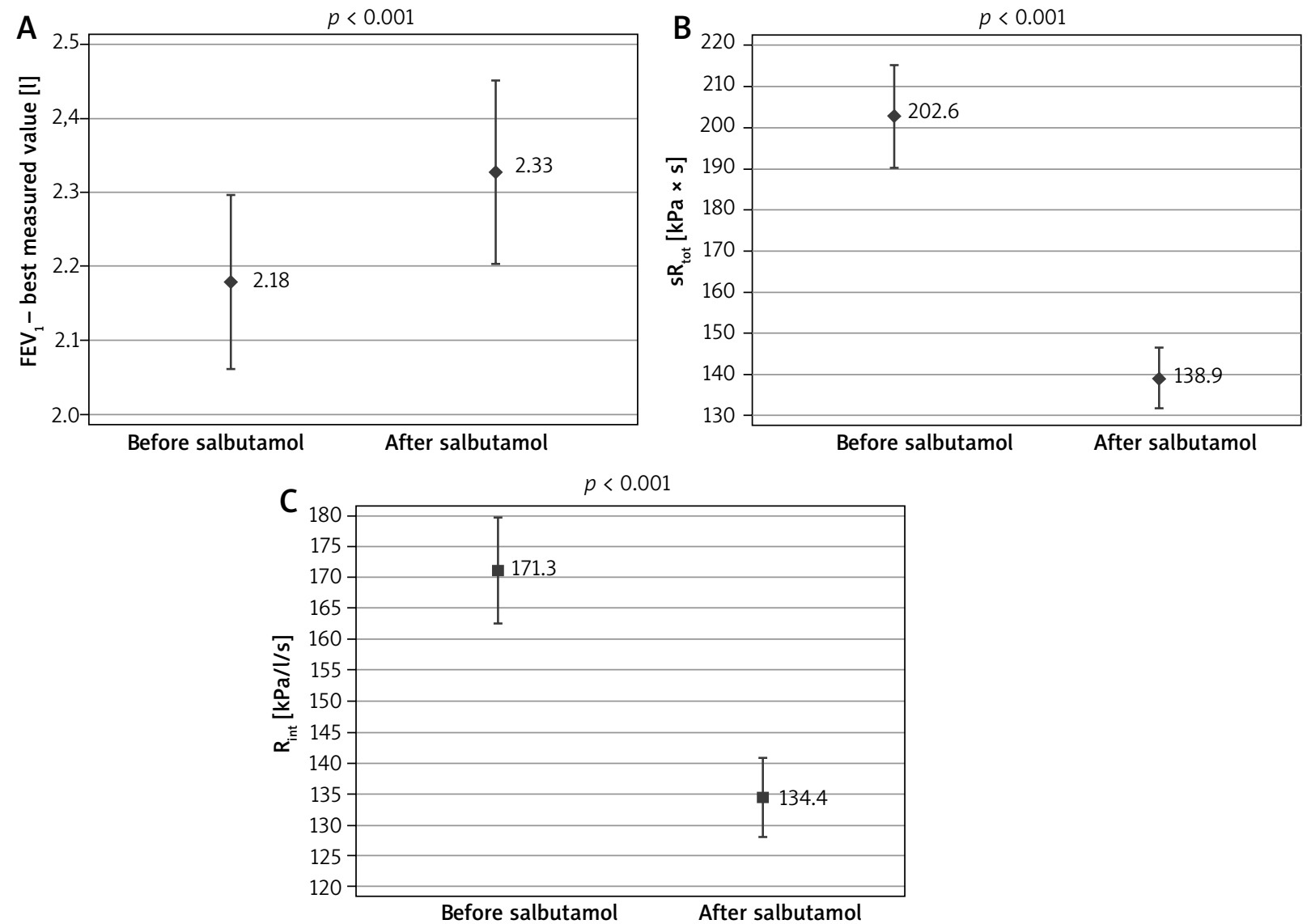

Figure 1. Forced expiratory volume in $1 \mathrm{~s} \mathrm{(FEV)} \mathrm{(A),} \mathrm{total} \mathrm{specific} \mathrm{resistance} \mathrm{(sRtot)} \mathrm{(B)} \mathrm{and} \mathrm{interrupter} \mathrm{resistance} \mathrm{(Rint)} \mathrm{(C)}$ results comparison in reversibility bronchodilator test

them plethysmography and 131 - the interrupter technique (not all parents gave permission to perform all tests as they were afraid of the children's condition). Two children were not able to repeat spirometry after admission of $\beta_{2}$-agonist. Perennial and/or seasonal allergy was diagnosed in all patients.

All investigated parameters changed statistically significantly after the bronchodilator administration in the examined patients (Table 1). Comparison of FEV , sRtot and Rint results in BT in studied children is shown in Figure 1. The bronchodilator administration procedure yielded an improvement in $\mathrm{FEV}_{1}$ by at least $12 \%$ in $26.7 \%$ of the study participants. Concerning the plethysmography, sRtot decreased $\geq 25 \%$ in $59.7 \%$, and $\geq 35 \%$ in $35.6 \%$, while Rint $\geq 25 \%$ in $50.4 \%$ and $\geq 35 \%$ in $16.3 \%$ of children (Figure 2). The absolute change (decrease, to be precise) in Rint was $38.86 \mathrm{kPa} / / \mathrm{s}$. The absolute change in its $z$-score was 0.0538 (that is, as a result of $0.7917-0.7379$ ). The logistic regression confirmed that the $\mathrm{FEV}_{1}$ was not so useful in diagnosis of asthma as the remaining two assessments, taking into consideration that all study participants had been correctly diagnosed with asthma ( $p<$ 0.001). The differences between the sRtot and Rint were not statistically significant in this context $(p=0.215)$.

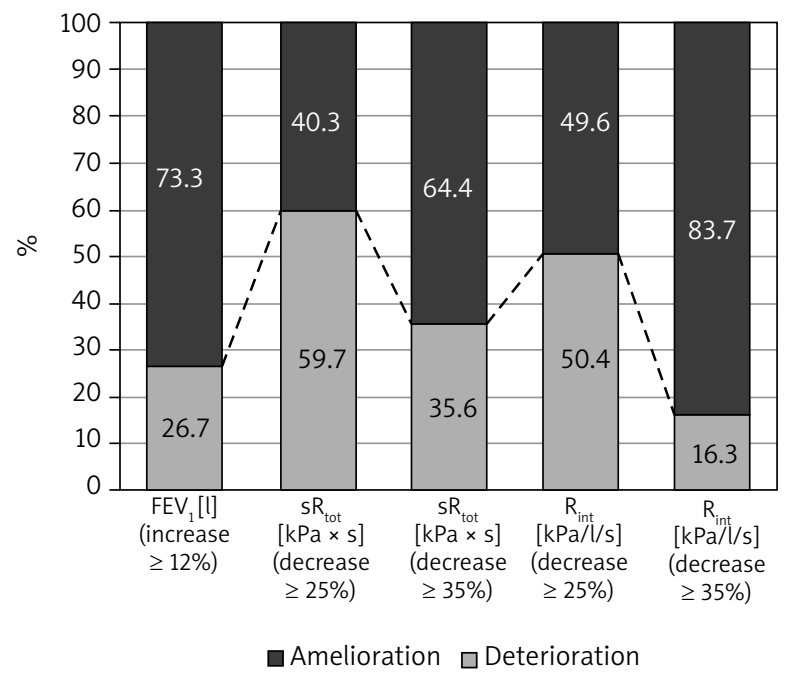

Figure 2. Changes in selected parameters after salbutamol intake $(p<0.001)$

\section{Discussion}

We assessed usefulness of sRtot and Rint in the bronchodilator reversibility test alternative to $\mathrm{FEV}_{1}$ in standard clinical practice in children with asthma symptoms in the 
allergy out-patient clinic. The results indicated that sRaw and Rint performed better in a bronchial reversibility test taking into account that asthma was diagnosed in all participants in the asthma diagnostic process. Studies that have investigated the effect of bronchodilation on sRaw in young children have demonstrated reversibility with $500 \mu \mathrm{g}$ of inhaled terbutaline (equivalent to $200 \mu \mathrm{g}$ of salbutamol) [9, 13]. We administered $400 \mu \mathrm{g}$ of salbutamol according to recommendations of ATS/ERS guidelines [2] and decided to use a spacer to avoid problems using a metered-dose inhaler (MDI) alone. Dose selection was supported by observation of Visser et al., who found significantly greater mean $\mathrm{FEV}_{1}$ reversibility after inhaling $400 \mu g$ salbutamol compared to $200 \mu g$ [14].

Evidence indicates that even in children below 6 years of age, pulmonary function tests produce technically satisfactory measurements using tidal breathing, the interrupter technique and forced oscillation [15-17] However, the clinical utility in the management of the individual child needs careful consideration. Also, in some asthmatics, bronchodilator tests can be negative; a possible explanation is that airway acidification does not affect pulmonary function [18]. Our study used spirometry, plethysmography and interrupter technique to demonstrate airway reversibility in children. There are limited studies comparing the above respiratory tests in paediatric population. Black et al. proved a good correlation between the interrupter technique and spirometry or plethysmography [16]. In another study, it was demonstrated that sRtot was more sensitive than $\mathrm{FEV}_{1}$, and Rint in detecting bronchoconstriction in normal subjects [19]. Nielsen and Bisgaard compared the results of three different lung function techniques in asthmatic children during measurement of the bronchodilator response [9]. They concluded that sRaw has the highest discriminative capacity and serves as the most sensitive method in assessing bronchodilator responsiveness. Additionally, they suggested three standard deviation (SD) units (corresponding to a change of $25 \%$ ) as the optimal cut-off level for discriminating between healthy children and asthmatic children. In our previous study we showed that sRtot (cut-off level - change of $\geq 25 \%$ in the prebronchodilator sRtot) was more sensitive and specific in identifying children with reversible obstruction than spirometry [6]. Sonnappa et al. measured multiple-breath washout indices (lung clearance index, conductive ventilation inhomogeneity (Scond)) and specific airway resistance (sRaw) in stable wheezers and in healthy children. Significant bronchodilator reversibility was only observed in wheezers for Scond but in both wheezers and healthy controls for sRaw, which is undermining the discriminating capacity of this technique in young children [20]. The results of our previous real-life study on 6439 children showed the lack of importance of sRaw in asthma diagnosis in schoolchildren [10]. This could be possibly explained by its overly high variability in schoolchildren, or a weak relationship between baseline $\mathrm{FEV}_{1}$ and sRaw, which was previously reported [21]. In another study, we suggested that in children with asthma-like symptoms at risk of the delayed asthma diagnosis, the spirometry together with the plethysmography should be performed to prevent underestimation of reversibility of bronchial obstruction and to increase the likelihood of early asthma detection [11].

In summary, parameters measured in our study may be useful in the diagnosis of asthma. However, the diagnosis of asthma is a clinical diagnosis that does not depend on bronchodilator responsiveness which may or may not be present at any specific time of measurement, especially when asymptomatic. Moreover, the total airway resistance is greatly influenced by the large airways which have the greatest component of airway resistance whereas disease is primarily present in the smaller airways. But the clinical advantages for measurements of small airway function, although potentially more relevant and can be estimated from some spirometry measurements, are not established. Therefore, our study has some limitations. Measure of overall airway resistance like sRtot or Rint is very sensitive to central airway pathology but less sensitive to peripheral changes. Also intra-subject variability in resistance measurements is much higher (5-15\%) in comparison to $3-5 \%$ in $\mathrm{FEV}_{1}$ [5]. Another concern is the cut-off point, as some literature sources suggest $40 \%$ and some may suggest up to $50 \%$ change as significant [5]. In our study we used the $25 \%$ and $35 \%$ cut-off for resistance change. Lower cut-off for significance may be the cause of the increase in the number of positive cases in resistance improvement as compared to significant FEV 1 change in this study. Contrariwise the $35 \%$ cut-off for resistance change has less sensitivity and may lead to underdiagnosis of asthma. In our patients, sRtot decreased $\geq 25 \%$ in $59.7 \%$, and $\geq 35 \%$ in $35.6 \%$, while Rint $\geq 25 \%$ in $50.4 \%$ and $\geq 35 \%$ in $16.3 \%$ of children. The limitation of our study is the lack of the control group of healthy children. However data on healthy children were published in the past. A study done on healthy preschool children revealed mean bronchodilator-induced changes (\% of predicted values) - 15\% for inspiratory Rint and 12\% for expiratory Rint [21, 22]. In another study, a 35\% decrease in resistance after bronchodilation expressed as the percentage of predicted value allowed for separating children with and without asthma [23]. According to ATS statement, a bronchodilation test using the interrupter technique should be considered clinically significant when the decrease in Rint after bronchodilator exceeds within-occasion repeatability between two sets of measurements established in 30 to 50 subjects for each individual laboratory [4]. Further studies are needed to establish the cut-off value for a decrease in airway resistance beyond which bronchodilator response should be considered clinically significant. 
Our study suggests the interrupter technique can be successfully used to measure the response to the bronchodilator in the asthma diagnostic process in children. The main advantages of the interrupter technique, as described by Child, are that it is an easy, cheap, noninvasive, effort-independent measurement, reproducible in children as young as 2-3 years old and helpful in assessing bronchodilator responsiveness [24]. According to Black et al. [16], the interrupter technique may have a role in assessing baseline airway function and response to therapy in children unable to perform reliable spirometry, and/or when the investigators wish to avoid the possible influence of forced manoeuvres on airway tone.

\section{Conclusions}

Our results suggest that sRtot and Rint may be useful parameters in the reversibility test in clinical practice in the asthma diagnostic process in children. The above parameters could serve as a reliable tool in the evaluation of children with asthma-like symptoms. Finally, our results call for other studies, with an adequate sample size, addressing the usefulness of sRtot and Rint in diagnostics of asthma in children, giving high quality evidence to incorporate the plethysmography and interrupter technique into standard guidelines for the management of asthma in children. In summary, there may be use of resistance measurement mainly in children who cannot do spirometry, but it does not replace FEV ${ }_{1}$ because of its intrinsic multiple issues. Also, some new methods should be applied for evaluation of airway obstruction in children, such as structured light plethysmography [25].

\section{Acknowledgments}

The work was financed from the means of the statutory funds of the Medical University of Lodz No. 503/2056-01/503-2-001, 503/6-029-01/503-61-001.

\section{Conflict of interest}

The authors declare no conflict of interest.

\section{References}

1. From the Global Strategy for Asthma Management and Prevention, Global Initiative for Asthma (GINA) 2018. Available from: http://www.ginasthma.org/.

2. Pellegrino R, Viegi G, Brusasco RO, et al. Interpretative strategies for lung function tests. Eur Respir J 2005; 26: 948-68.

3. Kirkby J, Stanojevic S, Welsh L, et al. Reference equations for specific airway resistance in children: the Asthma UK initiative. Eur Respir J 2010; 36: 622-9.

4. Beydon N, Davis SD, Lombardi E, et al. An official American Thoracic Society/European Respiratory Society Statement: Pulmonary Function Testing in Preschool Children. Am J Respir Crit Care Med 2007; 175: 1304-45.

5. Kaminsky DA. What does airway resistance tell us about lung function? Respir Care 2012; 57: 85-96.
6. Jerzynska J, Janas A, Galica K, et al. Total specific airway resistance vs spirometry in asthma evaluation in children in a large real-life population. Ann Allergy Asthma Immunol 2015; 115: 272-6.

7. Gosselink R, Stam H. Lung Function Testing. European Respiratory Monograph 2005; 15-43.

8. Frey U, Merkus PJFM. Paediatric Lung Function. European Respiratory Monograph 2010; 66-86.

9. Nielsen KG, Bisgard H. Discriminative capacity of bronchodilator response measured with three different lung function techniques in asthmatic and healthy children aged 2 to 5 years. Am J Respir Crit Care Med 2001; 164: 554-9.

10. Grzelewski T, Witkowski K, Makandjou-Ola E, et al. Diagnostic value of lung function parameters and FeNO for asthma in schoolchildren in large, real-life population. Pediatr Pulmonol 2014; 49: 632-40.

11. Brzozowska A, Majak P, Grzelewski T, et al. Measurement of specific airway resistance decreased the risk of delay in asthma diagnosis in children. Allergy Asthma Proc 2009; 30: 47-54.

12. Mercus PJ, Mijnsbergen JY, Hop WC, et al. Interrupter resistance in preschool children: measurement characteristics and reference values. Am J Respir Crit Care Med 2001; 163: 1350-5.

13. BTS/SIGN. British guideline on the management of asthma. A national clinical guideline 2016.

14. Visser R, Kelderman S, de Jongh FHC, et al. Reversibility of pulmonary function after inhaling salbutamol in different doses and body postures in asthmatic children. Respir Med 2015; 109: 1274-9.

15. Klug B, Bisgaard H. Measurement of the specific airway resistance by plethysmography in young children accompanied by an adult. Eur Respir J 1996; 10: 1599-605.

16. Black J, Baxter-Jones A D, Gordon J, et al. Assessment of airway function in young children with asthma: comparison of spirometry, interrupter technique and tidal flow by inductance pletysmography. Pediatr Pulmonol 2004; 37: 548-53.

17. Phagoo SB, Wilson NM, Silverman M. Evaluation of a new interrupter device for measuring bronchial responsiveness and the response to bronchodilator in 3 year old children. Eur Respir J 1996; 9: 1374-80.

18. Caffarelli C, Povesi Dascola C, Peroni D, et al. Airway acidification in childhood asthma exacerbations. Allergy Asthma Proc 2014; 35: e51-6.

19. Phagoo SB, Watson R, Silverman M, et al. Comparison of four methods of assessing airflow resistance before and after induced airway narrowing in normal subjects. J Apply Physiol 1995; 79: 518-25.

20. Sonnappa S, Bastardo CM, Wade A, et al. Repeatability and bronchodilator reversibility of lung function in young children. Eur Respr I 2013; 42: 116-24.

21. Beydon N, Mahut B, Maingot L, et al. Baseline and post-bronchodilator interrupter resistance and spirometry in asthmatic children. Pediatr Pulmonol 2012; 47: 987-93.

22. Beydon N, Amsallen F, Beller M, et al. French Pediatric Programme Hospitalier de Recherche Clinique Group. Pre/postbronchodilator interrupter resistance values in healthy young children. Am J Respir Crit Care Med 2002; 165: 1388-94.

23. Beydon N, Pin I, Matran R, et al. Pulmonary function tests in preschool children with asthma. Am J Respir Crit Care Med 2003; 168: 640-4.

24. Child F. The measurements of airways resistance using the interrupter technique (Rint). Paediatr Respir Rev 2005; 6: 273-7.

25. Ghezzi M, Tenero L, Piazza M, et al. Feasibility of structured light pletysmography for the evaluation of lung function in preschool children with asthma. Allergy Asthma Proc 2018; 39: e38-42. 